\title{
Performance of seasonal forecasts of Douro and Port wine production
}

\author{
João A. Santos ${ }^{\mathrm{a}, *}$, Andrej Ceglar ${ }^{\mathrm{b}}$, Andrea Toreti ${ }^{\mathrm{b}}$, Chloé Prodhomme ${ }^{\mathrm{c}, \mathrm{d}}$ \\ ${ }^{\text {a } C e n t r e ~ f o r ~ t h e ~ R e s e a r c h ~ a n d ~ T e c h n o l o g y ~ o f ~ A g r o-E n v i r o n m e n t a l ~ a n d ~ B i o l o g i c a l ~ S c i e n c e s, ~ C I T A B, ~ U n i v e r s i d a d e ~ d e ~ T r a ́ s-o s-M o n t e s ~ e ~ A l t o ~ D o u r o, ~ U T A D, ~ 5000-801 ~ V i l a ~}$ \\ Real, Portugal \\ ${ }^{\mathrm{b}}$ European Commission, Joint Research Centre, Via Enrico Fermi 2749, 21027 Ispra, Italy \\ ${ }^{\mathrm{c}}$ Group of Meteorology, Universitat de Barcelona (UB), Barcelona, Spain \\ ${ }^{\mathrm{d}}$ Barcelona Supercomputing Center (BSC), Torre Girona c/Jordi Girona, 31, 08034 Barcelona, Spain
}

\section{A R T I C L E I N F O}

\section{Keywords:}

Crop seasonal forecasts

Crop modelling

Wine production

ECMWF seasonal forecast system

Douro-Port wine region

Portugal

\begin{abstract}
A B S T R A C T
Wine production is intricately dependant on the evolution of weather conditions in a given year. Therefore, seasonal weather forecasts coupled with empirical wine production models can play a critical role in the short to medium-term management of vineyards and wineries. The implementation of suitable and timely adaptation measures based on predicted wine productions may contribute to risk reduction and improve efficiency. The performance of seasonal forecasts of wine production in the Portuguese Douro \& Port wine region (D\&P WR) is here assessed for the first time. This application may serve as a case study to be potentially extended to other wine regions. Here, we develop a predictive logistic model of wine production based on monthly mean air temperatures and monthly total precipitation, averaged over the periods of February-March, May-June, and July-September, complemented with an autoregressive component of wine productions. The wine production in the D\&P WR during the period 1950-2017 (68 years) is keyed into three classes: low, normal and high production years. The model reveals a correct estimation ratio of approximately $3 / 4$ for the full period, and $2 / 3$ when applied to independent 10\%-random subsamples. We then evaluate the performance of the ECMWF 7 month seasonal weather forecasts, issued from February to August, in predicting the meteorological conditions relevant for the wine production in the D\&P WR. Overall, the performance is satisfactory for the meteorological predictors. As for the weather forecasts coupled with the wine production model, results reveal that forecasts from May to August are strikingly the best performing, as 1) more observed data is integrated into the empirical model and 2) the skill of seasonal forecasts for summer months is higher. The operational application of these forecasts in the D\&P WR is already foreseen. Given the encouraging results, we believe this case study and the established methodology may be tested and adapted to other wine regions worldwide, with obvious benefits for the winemaking sector.
\end{abstract}

\section{Introduction}

Seasonal weather forecasts are becoming increasingly important across a wide range of sectors, such as agriculture, energy, water resources and insurance (Doblas-Reyes et al., 2013; Turco et al., 2017). Prediction of extreme events (such as the 2003 heatwave) on the seasonal time scale still represents a challenge in the extra-tropical regions (Weisheimer et al., 2011). However, new findings show the potential for a better understanding of the spatial and temporal features of these climatic events, along with associated precursors (Scaife et al., 2014; Prodhomme et al., 2016; Wang et al., 2017). The skill of seasonal forecasts is generally limited in Europe, but there are regions and seasons where significant skill appears as a result of processes like the ongoing climate change and/or soil processes, amongst others. Consequently, seasonal forecasts are an added value for the agricultural sector across Europe (e.g. Ceglar et al., 2018; Falloon et al., 2018). Although the assessments of seasonal forecast skills applied to the winemaking sector are still incipient, they are of foremost relevance, owing to the importance of this sector in the economy of many regions worldwide.

More specifically in Portugal, vitiviniculture is a key socioeconomic sector. According to the most recent data from the Portuguese governmental authorities (Instituto da Vinha e do Vinho, IVV; http://www. ivv.gov.pt/), the vineyard area in Portugal is of roughly 187000 ha (the 10th largest national vineyard area in the world). Portugal is the 11th wine producer and the 9th wine exporter worldwide (OIV, 2018).

\footnotetext{
*Corresponding author: João Carlos Andrade Santos, Departamento de Física, Universidade de Trás-os-Montes e Alto Douro, Quinta dos Prados, 5000-801 Vila Real, Portugal.

E-mail address: jsantos@utad.pt (J.A. Santos).
} 


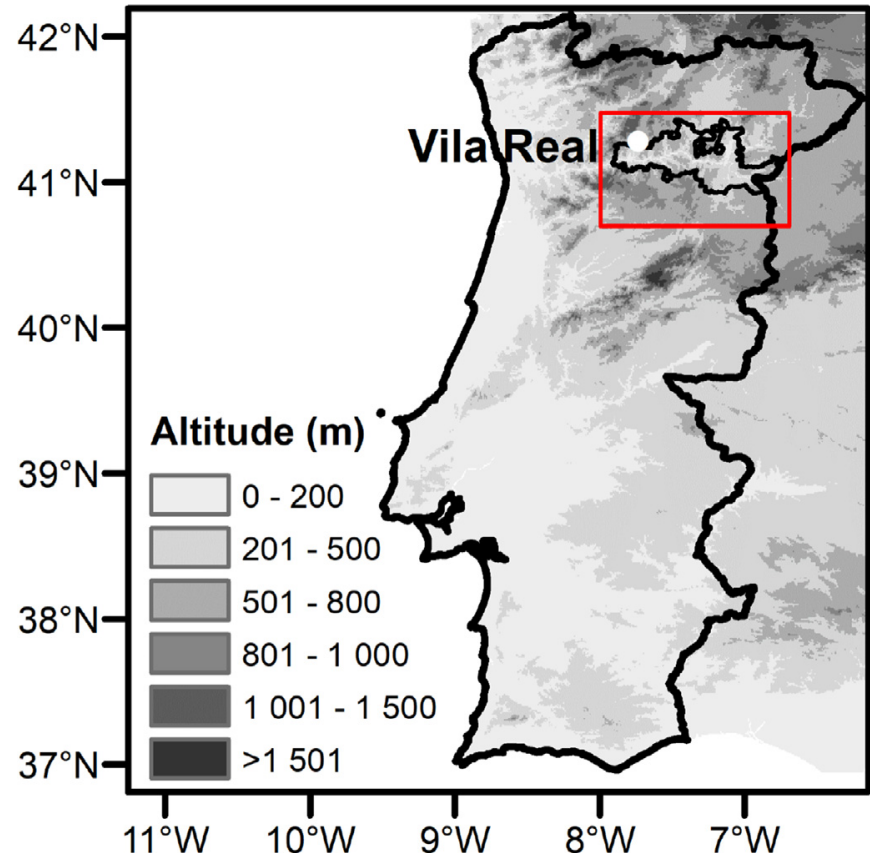

Fig. 1. Douro \& Port Wine Region: Hypsometric map of mainland Portugal with the geographical location of the Douro \& Port Wine Region. Seasonal weather forecasts were retrieved for grid cells within the outlined rectangle.

Although Mediterranean climatic conditions prevail, a large diversity of viticultural "terroirs" (van Leeuwen et al., 2004) and wine typicity (Drappier et al., 2019) can be found. Different mesoclimates, soils, cultural practices and grapevine varieties explain this diversity (Magalhães, 2008). This study targets the Douro \& Port wine region (D\&P WR henceforth), located in northern Portugal (Fig. 1), which comprises two conterminous Denominations of Origin (Douro \& Port). This region comprises a vineyard area of nearly 45000 ha, corresponding to approximately $22 \%$ of the total vineyard area in Portugal. It is responsible for $>40 \%$ of the Portuguese wine exports, dominated by the world-famous Port Wine (Gouveia et al., 2018). The D\&P WR features very complex orography, with a large diversity of terroirs (Fraga et al., 2017b). These different terroirs have strong implications on the chromatic and aromatic descriptors of the wines (PrataSena et al., 2018). A large number of autochthonous varieties can be found, but with low productivity (typically $<5000 \mathrm{~kg} \mathrm{ha}^{-1}$ ).

The D\&P WR is characterized by meso-Mediterranean climates, with annual mean temperatures within the range of $12-15{ }^{\circ} \mathrm{C}$, January means from 5 to $9{ }^{\circ} \mathrm{C}$ and July means from 21 to $25{ }^{\circ} \mathrm{C}$ (Costa et al., 2017). In terms of aridity/dryness, conditions vary from humid in the "Baixo-Corgo" (westernmost sector) and "Cima-Corgo" (central sector) sub-regions to sub-humid (i.e. annual totals of precipitation below evapotranspiration) in the "Douro Superior" (easternmost sector), with a strong east-west precipitation gradient, ranging from ca. 400 to $1200 \mathrm{~mm}$ (Costa et al., 2017). Precipitation is ubiquitously scarce in summer (June-August), typically less than $10 \%$ of annual precipitation, as it is strongly concentrated in autumn and winter, with large interannual variability (Costa et al., 2017).

Owing to the widely recognised sensitivity of the grapevine physiological development to weather and climate conditions, through several direct and indirect processes (Smart, 1985), grape berry quantity and quality reveal important inter-annual variability. Grapevine phenological timings are largely controlled by temperature (Malheiro et al., 2013), also influencing vineyard management and cultural practices. Hence, viticulture is at risk under climate change, as grapevine responses will be necessarily different under future climates (Moriondo et al., 2015; Fraga et al., 2016a; de Cortazar-Atauri et al.,
2017). This may threaten wine typicity and wine balance of a given region, or even, in more extreme circumstances, its viticultural suitability (Santos et al., 2020a).

In Portugal, where significant warming and drying trends are projected for the future, including enhancements in the frequency of occurrence of temperature and precipitation extreme events (Costa et al., 2012; Andrade et al., 2014; Santos et al., 2019b), viticulture is particularly vulnerable to climate change (Fraga et al., 2014a, 2016b, 2017a; Santos et al., 2019a). The strong connection between precipitation in Portugal and the large-scale atmospheric circulation is a major factor to take into account in future climate conditions. Shifts in the large-scale atmospheric patterns within the Euro-Atlantic sector will significantly increase the frequencies of occurrence of severe precipitation deficits and droughts (Santos et al., 2009, 2016). This will challenge the country's water resources (Andrade et al., 2011) and limit irrigation as a potential adaptation measure for viticulture (Fraga et al., 2018). More frequent and intense heatwaves are also an important hazard to be taken into account in future climates (Fraga et al., 2020).

In the D\&P WR, the strong inter-annual variability in grapevine yields and wine production has been associated to atmospheric forcing, while long-term trends have been linked to changes in cultural practices and management, as well as in national and regional policies, such as programmes devoted to vineyard plantation, restructuring or replacement (Santos et al., 2011, 2013). The pronounced interannual variability may have important impacts on phenology (e.g. budburst, flowering and veraison), yields, wine acidity and berry sugar content, thus challenging the stable production of high-quality wines (Santos et al., 2020a). Therefore, knowing in advance the potential wine production, based on seasonal climate forecasts, is of utmost relevance for the winemaking sector. Suitable adaptation measures can be applied to mitigate both the annual fluctuations in yields, in the short-term, and the climate change impacts, in the long-term. Changes in agricultural practices, such as pruning, application of sunscreens, cover crops, mulching, soil tillage, phytosanitary treatments, irrigation and genetics, are only a few examples of adaptation options (Duchene, 2016; Mosedale et al., 2016; Bernardo et al., 2018; Fraga et al., 2018; Fraga and Santos, 2018). Stock management in wineries is also a key aspect that can be better planned when predictions are available. All these measures may effectively reduce costs and improve the efficiency of the whole wine production chain, thus highlighting the need for reliable seasonal predictions of wine production. Although this study is focused on a specific wine region, similar methodologies can be implemented in other wine regions worldwide.

Along the previous lines, the present study objectives are threefold: 1) to develop a wine production model for the D\&P WR that can be operated with seasonal forecasts of meteorological variables, 2) to assess the skill of the seasonal weather forecasts in the D\&P WR, and 3) to evaluate the performance of the seasonal predictions of wine production in the D\&P WR. The first objective builds on the study by Santos et al. (2013), where a wine production model for the D\&P WR was developed. In that preceding study, climate model data were used to generate long-range projections of wine production, based on different anthropogenic forcing scenarios. Nevertheless, here, we develop a novel empirical wine production model aiming to integrate seasonal weather forecasts into medium-range regional wine production outlooks. To our knowledge, objectives 2) and 3) have not been addressed in any previous study. Data and methods are presented in Section 2, the main results in Section 3, followed by a discussion of the main results and the overall conclusions of the study.

\section{Material and methods}

\subsection{Wine production data}

We apply a multinomial logistic linear regression (Wilks, 1995) to model the wine production in the D\&P WR, northern Portugal (Fig. 1). 
(a)

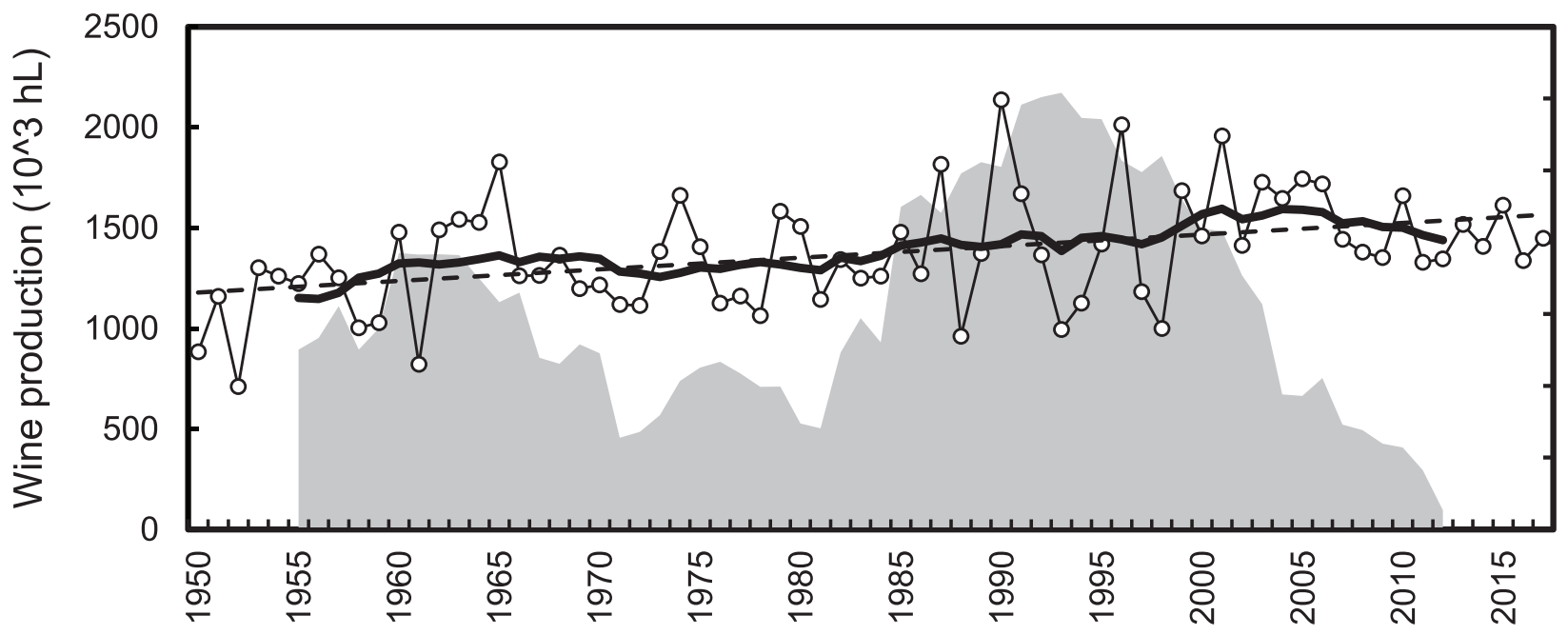

(b)

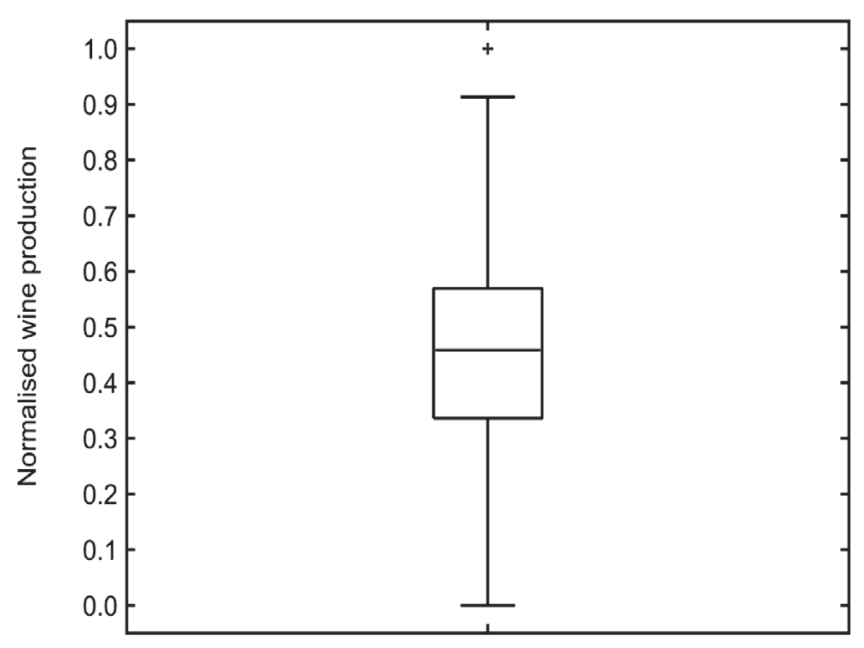

(c)

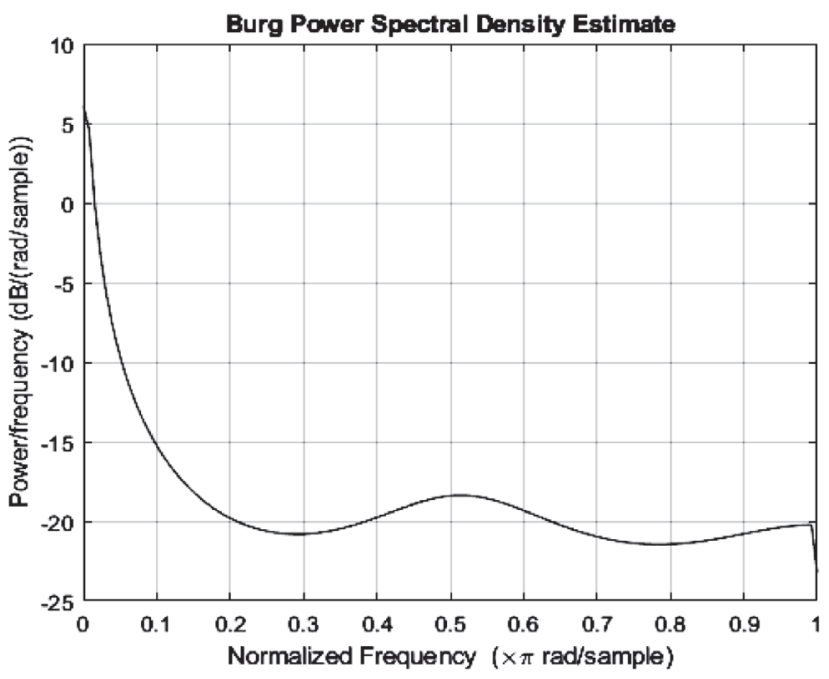

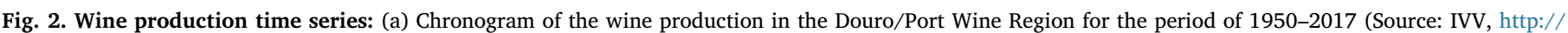

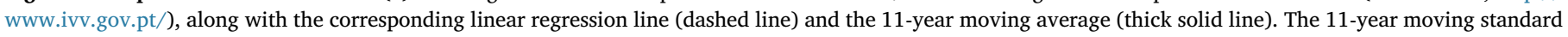

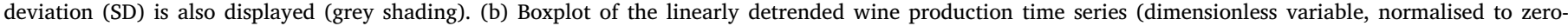

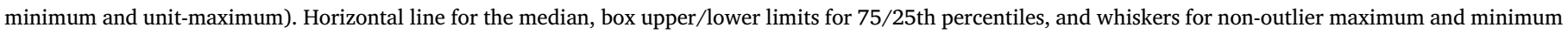
(outlier: 1990 production). (c) Burg's spectrum (power spectral density) of the linearly detrended wine production time series.

Since sub-regional or local/single "Quinta" (wine estates) time series tend to suffer from many inconsistencies and heterogeneities, we use the D\&P WR wine production time series (in $10^{3} \mathrm{hl}$ ) from the IVV (the entity responsible for monitoring and regulating regional wine production) over the period from 1950 to 2017 (Fig. 2a). This is a relatively long time series (68 years) compared to other Portuguese wine regions and was quality-controlled by IVV.

\subsection{Logistic regression}

In the development of the wine production model, we build on Santos et al. (2013). In that study, a logistic linear regression was applied to model wine production in the D\&P WR, using as exploratory variables the mean temperature from February to March, the mean temperature in May and the monthly total precipitation in March. The meteorological variables were obtained from a local weather station (Vila Real). As in that preceding study, the annual wine productions are first categorized into three classes: low [0 to $1 / 3$ quantile], normal] $1 / 3$ to $2 / 3$ quantile[and high [2/3 to 1 quantile]. As potential predictors, we test the mean (TG), minimum (TN) and maximum (TX) monthly temperatures, as well as monthly total precipitation (RR). These variables have been retrieved from the E-OBS dataset (19.0e version; Cornes et al., 2018), for the three grid cells covering the whole of the D\&P WR (their full extent is outlined by the rectangular sector in Fig. 1). The gridded data are then spatially averaged to obtain a single time series for each variable, on the monthly timescale and over the selected period (1950-2017). Using a gridded dataset (E-OBS) for model calibration is a clear advantage when the model is aimed to run with gridded simulated data from weather forecasts. Furthermore, the E-OBS dataset provides more homogeneous and representative information of the whole region than a single weather station. Nonetheless, a correlation analysis between these time series and the corresponding variables recorded at the weather station in Vila Real, located within the D\&P WR, showed correlation coefficients $>0.95$ for 
all variables (statistically significant at $1 \%$ level).

We then apply exploratory stepwise multivariate linear regressions (Wilks, 1995) between all potential predictors and wine production. The results show that: 1) TN and TX do not perform better than TG, 2) variables averaged over several months tend to perform better than monthly means, and 3) improvements are achieved when lagged wine production series are also incorporated in the model. The stepwise approach selects 11 exploratory variables (predictors): the average of monthly mean TG and monthly total RR from February to March, May to June and July to September (6 variables), and previous year wine production anomalies w.r.t. the five preceding years (five autoregressive variables). For the autoregressive variables, we use wine production data from 1945 to 1949 , obtained from the same source as the data from 1950 to 2017 (IVV). Finally, we fit a multinomial logistic regression model based on the aforesaid variables.

The selected meteorological variables are in general agreement with the grapevine growing season (April to October, in the Northern Hemisphere). The period from February to March corresponds to the end of the winter dormancy phase (Leolini et al., 2020), which culminates with grapevine budburst. April does not show statistically robust connections to wine production. The period from May to June is critical for flowering and veraison, two major phenological stages, whereas the period from July to September is determinant for grape berry maturation and for determining the technical harvest date (Smart, 1985; Magalhães, 2008). The autoregressive variables are coherent with the 2-year reproductive cycle of grapevines (Smart, 1985; Magalhães, 2008). As such, the identified periods correspond to critical stages of grapevine growth and development, which will ultimately determine yields and vintage wine production. The wine production model used in the present study significantly improves the one of Santos et al. (2013), as it considers new variables computed over different temporal windows, and incorporates an autoregressive component based on wine production series.

The probabilities of occurrence of the three wine production classes are thereby attained for 1950-2017. We assign the most probable class simulated by the model to each year and compare to the observed class. The "correct estimation ratio" is the fraction of correct assignments by the model for all years of the selected period (1950-2017). For validation purposes, the model performance is tested for $10 \%$-subsamples of independent data (verification subsamples), being the remaining $90 \%$ of the data used for model calibration (training subsamples). These subsamples are randomly selected from the 68 years of data, without repetition of years in the same subsample. In total, 1000 subsamples are considered. The correct estimation error calculated over all subsamples is then used as a validation performance metric.

\subsection{Seasonal weather forecasts}

For assessing the seasonal forecast skill of the wine production in the D\&P WR, we use an ensemble of 51 members/initializations of the ECMWF (European Centre for Medium-Range Weather Forecasts) seasonal forecast system 4 (S4; Molteni et al., 2011). Ensemble members reflect model integrations that run with slightly different initial conditions for the atmosphere and the ocean (Du et al., 2012; Balmaseda et al., 2013). The seasonal forecast of air temperature and total precipitation is performed on a horizontal resolution of nearly $0.7^{\circ}$ latitude $\times$ longitude. To evaluate the performance of the wine production forecasts (driven by seasonal weather forecasts), we use a set of retrospective forecasts emulating real predictions for a 30-year period (1981-2010), joined with the operational S4 forecast for the period 2011-2015. The lead time of forecasts is 7 months over the full period (1981-2015). Therefore, to allow the computation of all the above-mentioned meteorological predictors of the wine production model (averages of monthly TG and RR from February to September), we consider seasonal weather forecasts issued from February (forecasts available from March to September) until August (forecasts available from September to
March of the following year, only September is used). Seasonal forecasts are issued monthly, from February (before budburst) until August (close to harvest), thus covering the whole grapevine growing season.

All forecasted variables are bias-corrected on the monthly timescale using the aforementioned E-OBS variables as a baseline (1981-2015). E-OBS precipitation and temperature data are re-gridded to match the grid of seasonal forecasts. We apply conservational remapping for precipitation and bi-linear interpolation for air temperature. We apply a bias correction methodology based on non-parametric quantile mapping (Gudmundsson et al., 2012), with E-OBS re-gridded datasets used as an observed meteorological reference. We retrieve a single grid cell over northern Portugal, where the D\&P WR is located (Fig. 1).

To assess the weather forecast performance, we calculate the mean absolute error (MAE) of the simulated predictors as a function of the forecast month, i.e. the month when the forecast is issued (from February to August). For the predicted wine production in each forecast month, we compute the Gilbert skill score - GSS (Wilks, 1995) between seasonal forecasts of the different production classes, for all ensemble members, and the predicted production class based on the observed meteorological predictors. These scores provide a way of summarising the ability of a deterministic prediction to correctly forecast a dichotomous event. GSS measures the fraction of observed and/or forecast events that are correctly predicted, adjusted for hits associated with random chance. Score 1 is assigned to a perfect forecast, while random forecasts correspond to score 0 .

\section{Results}

\subsection{Analysis of the wine production time series}

Concerning the wine production series (Fig. 2a) from 1950 to 2017, no missing data exists and only a slight long-term linear trend is apparent (dashed line), though it is not statistically significant at a $5 \%$ significance level, according to the non-parametric Mann-Kendall test (Wilks, 1995). The 11-year moving averages (thick black line) also hint at the absence of a non-linear trend, thus showing that the background low-frequency variability is mostly represented by the linear regression curve (Fig. 2a). The 11-year moving standard deviations (SD, grey shading) reveal some non-stationarity in the variance, with a maximum in the period of 1986-2000 and a secondary maximum in the early 1960s (Fig. 2a). However, no consensual explanation was found for this behaviour, particularly for the strong fluctuations of the production in 1986-2000. As the regional climatic conditions do not reveal a similar pattern in SD (not shown), this behaviour might be related to non-climatic factors.

The linearly detrended time series is normally distributed according to the Lilliefors test and has no statistically significant serial autocorrelation (both tests performed at a $5 \%$ significance level). The corresponding boxplot and Burg's spectrum of the detrended wine production time series, normalized to zero-minimum and unit-maximum (dimensionless variable), reveal very low skewness (Fig. 2b) and some remaining background red-noise level, despite a secondary peak centred at about 4 years (Fig. 2c). This suggests some periodicities in wine production that may enable improving the model performance with the incorporation of auto-regressive variables. These oscillations in wine production may be explained by the 2 -year reproductive cycles and were already identified in previous studies (Fraga et al., 2014b). Thus, the wine production time series fulfils the elementary assumptions for multinomial logistic regression analysis (Wilks, 1995).

\subsection{Calibration and validation of the production model}

The application of the multinomial logistic regression model to the wine production data in the D\&P WR over the 68-year period is depicted in Fig. 3. As stated above, we consider 11 predictors, namely average of monthly mean TG and monthly total RR over the periods 
(a)

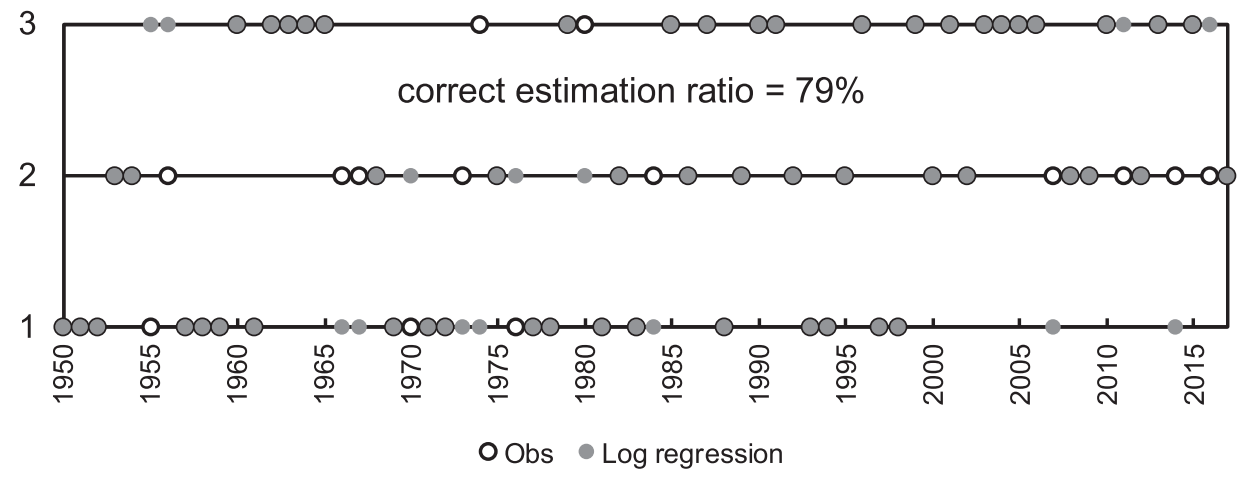

Fig. 3. Empirical wine production model: (a) Observed and modelled wine production classes (1-low, 2-normal and 3-high production) in the Douro/Port Wine Region, Portugal, from 1950 to 2017 (see legend for details). (b) Cumulative bar chart of the corresponding probabilities of occurrence (in\%) of the three wine production classes from the multinomial logistic regression model. The 11 exploratory variables are the average of monthly mean TG and monthly total RR over February to March, May to June and July to September (6 variables) and wine production anomalies for the previous 5 years (5 variables). Wine classes are defined as: low - [0 to $1 / 3$ quantile], normal -] $1 / 3$ to $2 / 3$ quantile[and high $-[2 / 3$ to 1 quantile].

(b)

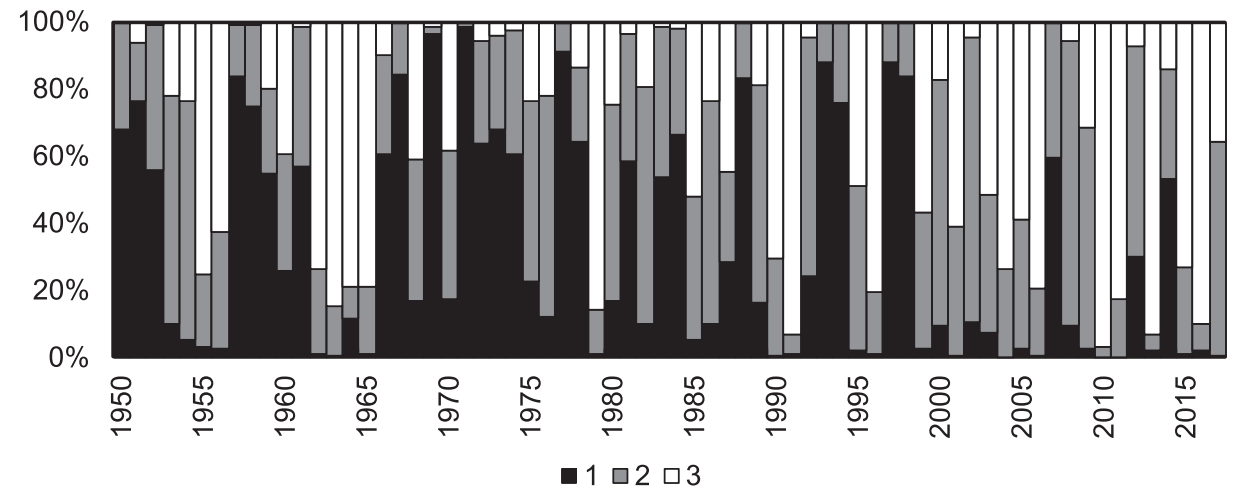

from February to March, May to June and July to September (6 variables) and wine production anomalies for the previous five years (5 variables).

Fig. 4 shows the normalized regression coefficients of the logistic model for class-3 (high production). As expected, for class-1 (low production) the coefficients are of opposite signal and similar magnitude

\section{Normalized regression coefficients for class-3 (high production)}

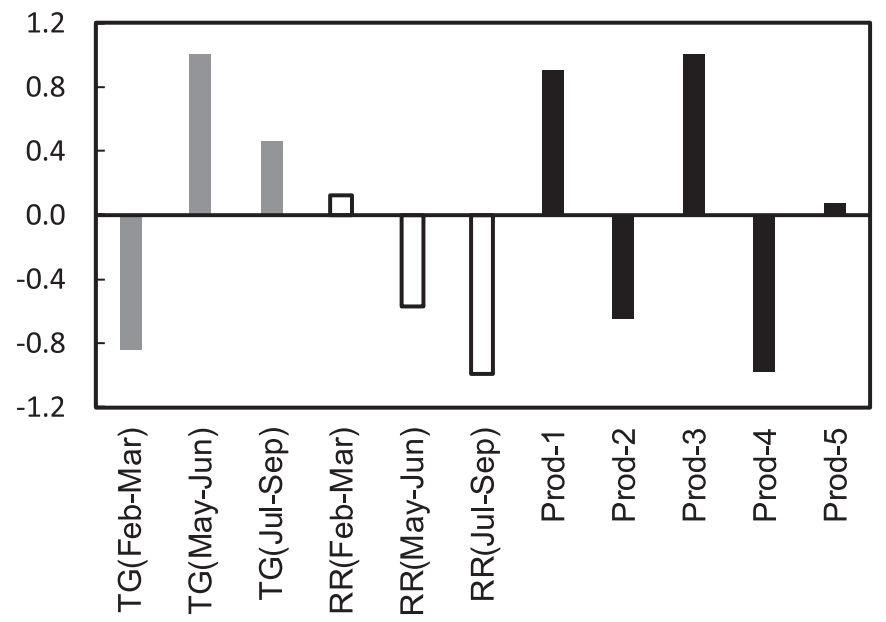

Fig. 4. Regression coefficients of the wine production model: Regression coefficients of the logistic regression model for class-3 (high production). The coefficients were normalized to a unit absolute maximum of each group of variables: TG (mean temperatures), RR (total precipitations) and Prod-i (previous year production anomalies w.r.t. the i th preceding year). (not shown). The coefficients reveal that anomalously cool and wet conditions in February-March are favourable to wine production; the same holds for anomalously warm and dry conditions in May-June and July-September, which is in clear agreement with previous studies (Santos et al., 2011, 2013). Precipitation in early spring usually provides enough soil moisture for grapevine development, while abundant precipitation at later stages can be particularly harmful, triggering phytosanitary risks in the vineyards caused by outbreaks of pests and diseases (Santos et al., 2020a). Moderate cool temperatures in early spring are useful to avoid an excessive advancement of the phenological stages, such as budburst, which may increase e.g. late frost risk (Santos et al., 2020a). Conversely, moderately warm temperatures in late spring and summer are normally favourable to the grapevine growth and development, promoting higher yields (Santos et al., 2020a). Furthermore, when the previous year experienced higher production than the year before, the production also tends to be higher and a three-year oscillation is found in the regression coefficients back to 5 years (Fig. 4), which is in accordance to the reproductive cycle of grapevines (Magalhães, 2008; Santos et al., 2020a).

The observed and modelled wine production classes (1-low, 2normal and 3-high production) reveal an overall good agreement, with a correct estimation ratio of $79 \%$, i.e. 53 years out of 68 are accurately estimated by the model (Fig. 3a). Of the 14 years that are not accurately estimated, 3 are in class- 3,2 in class- 1 and 9 in class- 2 . Hence, the model can simulate most of the extreme years, as the majority of the inconsistencies are indeed in class-2 (normal production). These false classifications correspond to years in which normal wine production is reported despite the unfavourable meteorological conditions, which let the model suggests anomalously higher/lower production. In part, these discrepancies can be explained by several measures applied by the winemaking sector to stabilize production. Regardless of the production class, years with false classifications are spread throughout the study 
period, not revealing any clear temporal dependency or systematic bias. The most striking discrepancies are for 1955 when the model estimates high production while low production was observed, and for 1974 when the model estimates low production and high production was observed instead. However, we have no consistent explanation for these two extreme years. It is important to bear in mind that only atmospheric mean conditions are taken into account in the present model, thus not taking into account extreme weather episodes (e.g. frost, hail, wind gusts or heavy precipitation) or weather-driven extreme events (landslides) that may significantly alter annual production. Furthermore, many other wine production-controlling factors, such as management measures in both the vineyards and the wineries, which often envision a stabilization of the annual wine production, are also not taken into account by this model. These decisions may lead to "normal" production years even under anomalous atmospheric conditions, which may underlie some of the above-stated discrepancies between estimated and observed productions.

The probabilities of occurrence of the three wine production classes (Fig. 3b) complement the information provided above, also highlighting the probabilistic (not deterministic) nature of the model. High probabilities of occurrence can be found in a given class for some years (ca. $99 \%$ for class-1 in 1971), while very balanced probabilities are found for other years (e.g. 1960). For each year, the probabilities of occurrence of each class are indeed much more informative than providing only the most probable class, enabling a better judgement of the prediction. As described above, we have tested the model performance in $100010 \%$-subsamples of independent data, randomly selected from the full period. The correct estimation ratio averaged over all subsamples is of $67 \%$. This value reveals a good performance against a ratio of approximately $33 \%$ obtained using a randomly generated wine production series from a uniform probability distribution (random process with equal probability for each of the three classes), i.e., without the correlation structure between production and the predictors.

Although we follow a similar statistical approach as in Santos et al. (2013), the wine production model is notably modified, by integrating new variables, defined over new temporal windows, and by considering autoregressive variables. Moreover, the model calibration and validation is carried out using the gridded E-OBS dataset instead of a single local weather station (Vila Real). The gridded data are more homogenous and representative of the entire D\&P WR than the singlesite meteorological data. These features may explain the identification of more robust relationships between the wine production records for the whole D\&P WR and the meteorological elements, thus allowing the incorporation of additional predictors in the model and enhancing its overall performance.

\subsection{Performance of seasonal forecasts of atmospheric variables}

Monthly forecasts with a lead time of 7 months are issued from January (forecast covering the period from February to August) to August (forecast covering the period from September to March of the following year). To assess the performance of these seasonal forecasts, the MAE of monthly TG and RR are shown in Fig. 5a,b. For each monthly variable and forecast month, we compute the MAE between the corresponding ensemble mean of the 51 forecast members and the corresponding E-OBS mean over the full period of 1981-2015. It should be mentioned that no biases in the means exist, as data was previously bias-corrected. As such, MAE only reflects the inter-annual variability of the departures between ensemble means and E-OBS.

The MAE maximum in the period from March to May, apparent in both variables (MAE $>1.1{ }^{\circ} \mathrm{C}$ in TG and $>30 \mathrm{~mm}$ in RR), can be explained by the fact that these months correspond to the transition from wintertime to summertime regimes, thus with higher uncertainty in weather conditions. As an illustration, the forecast issued in January reveals a gradual increase in MAE of TG (or RR) until April (or March), but a decrease can be found thereafter. Similar considerations hold for
September. In general, the MAE of TG and RR depict strong seasonality. As a Mediterranean-type climate, with scarce summer precipitation, MAE of RR in July and August are very low $(<10 \mathrm{~mm})$. Therefore, for a given forecast issue, it is clear that the forecast skill does not necessarily decrease with time. In climates with strong seasonality, the skill may indeed increase with time over periods when weather conditions are typically more settled and persistent. As the empirical model predictors are based on these monthly means, the above-mentioned forecast errors are expected to directly influence the forecast skill of the former variables.

We now assess the accuracy of the monthly forecasts of each predictor by the corresponding MAE, as a function of the forecast month, from February to August (Fig. 5c,d). MAE is non-zero for TG(Feb-Mar) in February, TG(May-Jun) from February to May, and TG(Jul-Sep) from February to August, as for the respective following month each variable will be entirely defined by observations (with zero MAE). Similar considerations can be made for the three RR variables. As expected, gradually lower errors are found as observational data is integrated into the model predictors. Regarding TG(May-Jun) and RR(May-Jun), there are no significant decreases of MAE until May (MAE $>1.0^{\circ} \mathrm{C}$ ), when the observed TG or RR for this month is incorporated in the corresponding predictor. As such, in line with the previous considerations concerning the high uncertainty in spring TG and RR (Fig. 4), we have not identified higher skill for these two variables with time. For TG(Jul-Sep) and RR(Jul-Sep), analogous inferences can be made, as only in July and August the MAE consistently decreases. In general, these findings highlight that the seasonal forecasts of TG and RR for the D\&P WR are coherent with the E-OBS observational dataset, and can then be consistently coupled with the logistic model to generate predictions for the regional wine production.

\subsection{Performance of seasonal forecasts for wine production classes}

When the production model is run with the forecasted variables (51member ensemble means), the ratio of correct predictions (in\%) by forecast month gradually increases, approaching the ratio obtained when the model is run only with the E-OBS observational data (Fig. 6). For the sub-period with seasonal forecasts (1981-2015), the ratio of correct predictions using E-OBS is higher than for the whole period (1950-2017), being equal to $89 \%$ instead of $79 \%$. The probably higher data quality in the most recent sub-period, in both meteorological variables and wine production, may explain this improvement in the wine production model performance.

For July and August, the number of correct predictions of the wine production class is of approximately $80 \%$, while for May and June the values are of $71 \%$ and $77 \%$, respectively. This can be considered as a good result owing to the simplicity of the approach, to the complexity of the wine production-controlling factors and their multiple interactions, as well as to the still existing limitations in seasonal weather forecasts for the study region. Although the forecast skill is relatively low for February, March and April, it is within the interval from $46 \%$ to $57 \%$ (the ratio of correct predictions in a purely random prediction process is $1 / 3$, i.e. approximately $33 \%$ ). Hence, although the monthly forecasts from May to August provide much higher predictive potential, the forecasts from February to April may also be considered a useful decision support tool, giving already some clues about the wine production for a given year, with several months in advance.

The previous findings are based on the 51 -member ensemble means of the forecasted meteorological variables. Nonetheless, information on the ensemble internal variability is of major relevance for an accurate assessment of the actual predictive potential. GSSs are calculated to provide measures on how seasonal wine production forecasts correspond to different levels of the observed wine production. For this purpose, the GSSs are shown in matrix charts (Fig. 7), by forecast month (February to August, $\mathrm{x}$-axis) and wine production class (1-low, 2normal and 3-high, y-axis). These charts depict GSS in a greyscale, 
(a)

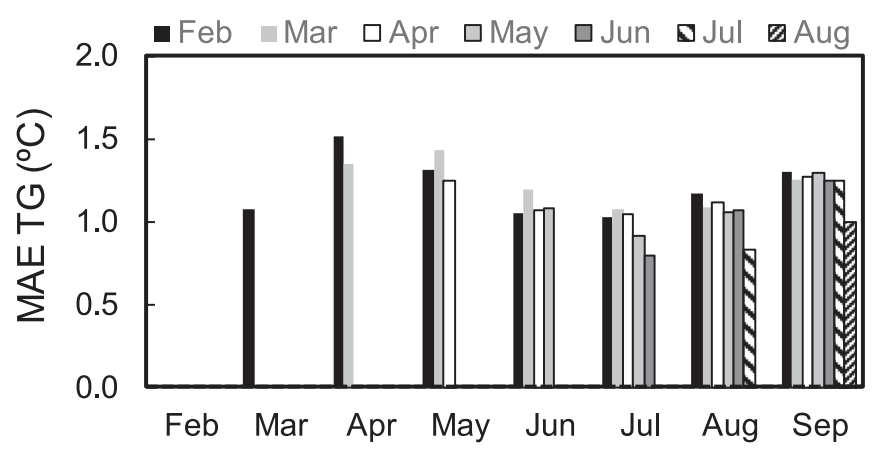

(c)

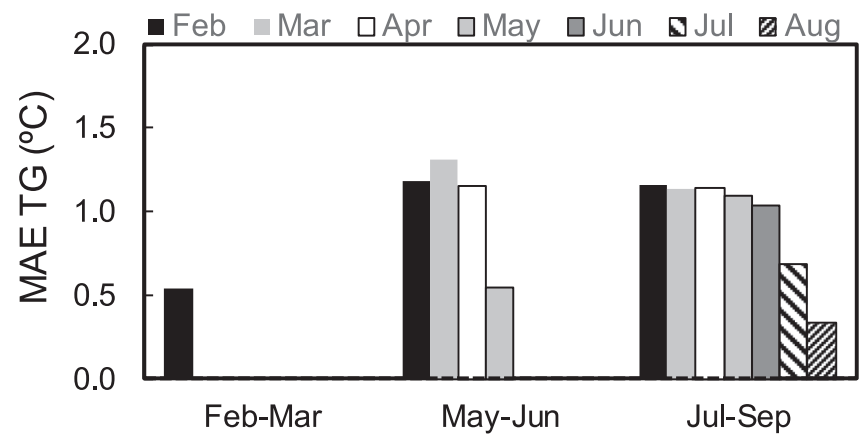

(b)

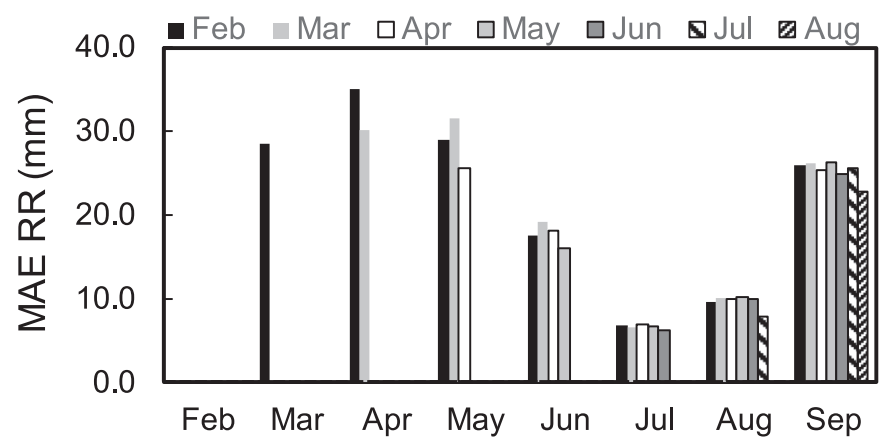

(d)

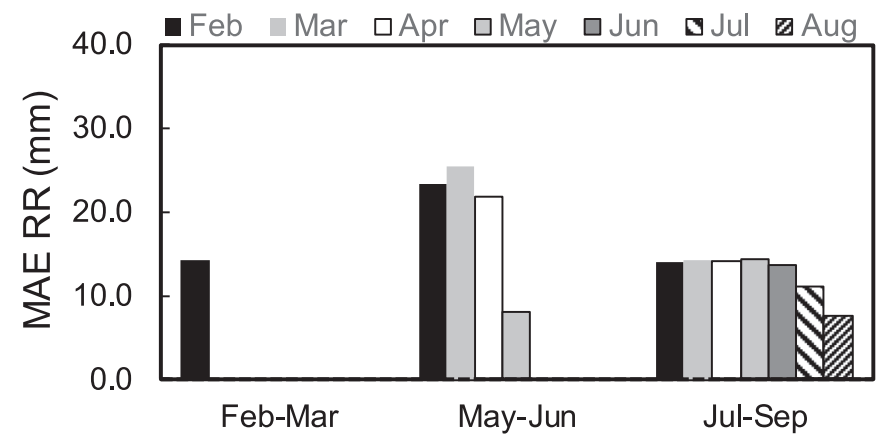

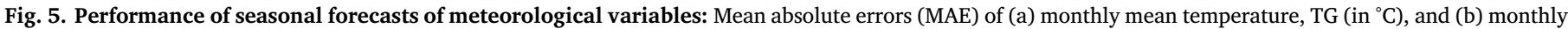

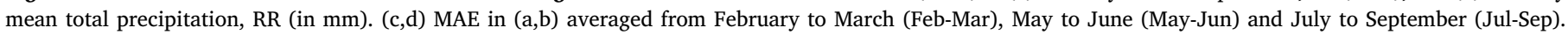

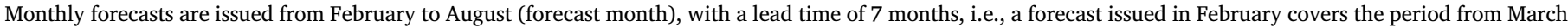

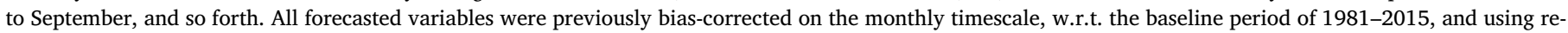
gridded E-OBS data covering the D\&P WR.

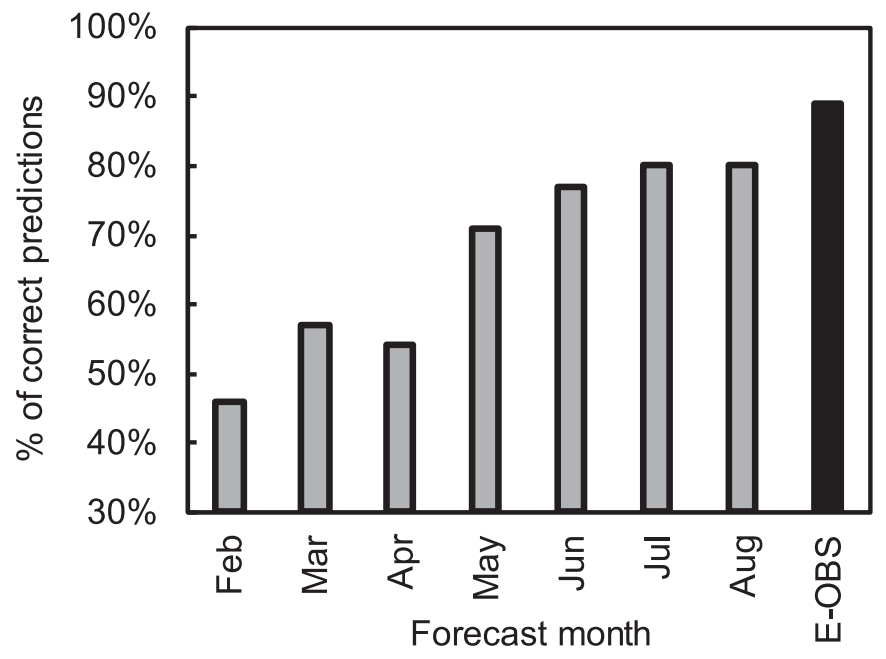

Fig. 6. Performance of wine production predictions: Ratio of correct predictions (in \%) by forecast month. The ratio obtained when the wine production model is run with meteorological observational data is also shown (E-OBS), which is equal to the observed wine production class for $89 \%$ of the years. In January is not possible to issue production forecasts as model data is not available until September (forecast period of 7 months). The lower graph limit of $30 \%$ is of approximately $1 / 3$, i.e. the probability of a random correct prediction of the wine production class.

ranging from 0 (no skill) to 1 (perfect skill). The scores are assessed either using the estimated wine production class, indirectly obtained from the logistic model driven by the E-OBS observational data
(Fig. 7a), or the directly observed class (Fig. 7b). As expected, the GSSs are slightly lower when considering the observed rather than the estimated wine production class. In fact, the direct comparison with the observed production classes comprises the uncertainties in both the weather forecasts and the logistic model, thereby explaining the lower skill scores. The skill of seasonal predictions is dependant on the proportion of seasonal forecast ensemble members (threshold) that lead to the same wine production class (ensemble agreement on the correct class). Thus, matrix charts for thresholds varying from 0.5 ( $50 \%$ of the members agree with the correct class) to 1 (all ensemble members agree with the correct class) are displayed (Fig. 7).

Overall, the outcomes hint at high skill in the seasonal predictions from May onwards, particularly for low production years (Fig. 7). The lowest skill belongs to the 1-ratio probability threshold, i.e. all ensemble members agree on the production class. In this case, skill scores above 0 only characterize seasonal production forecasts issued from May until August, with the highest skill observed in August. The member agreement is relatively low and, therefore, the skill tends to be higher for lower thresholds (from 0.5 to 0.9-ratios), i.e., when smaller fractions of the ensemble members are used for the prediction of an event. In effect, for lower thresholds, some relevant skill appears for seasonal forecasts issued earlier in the year, mostly for normal and high wine production classes. Conversely, for low production years, the skill remains low independently of the considered threshold for start dates before May. One tentative explanation for this differentiated response is the possibly stronger dependency of the occurrence of low production years on unfavourable summertime conditions and extreme events, such as heatwaves and severe droughts. Regardless of the threshold taken and the wine production class, the seasonal forecast skill is manifestly higher in summer months. Thus, these outcomes highlight 
a)

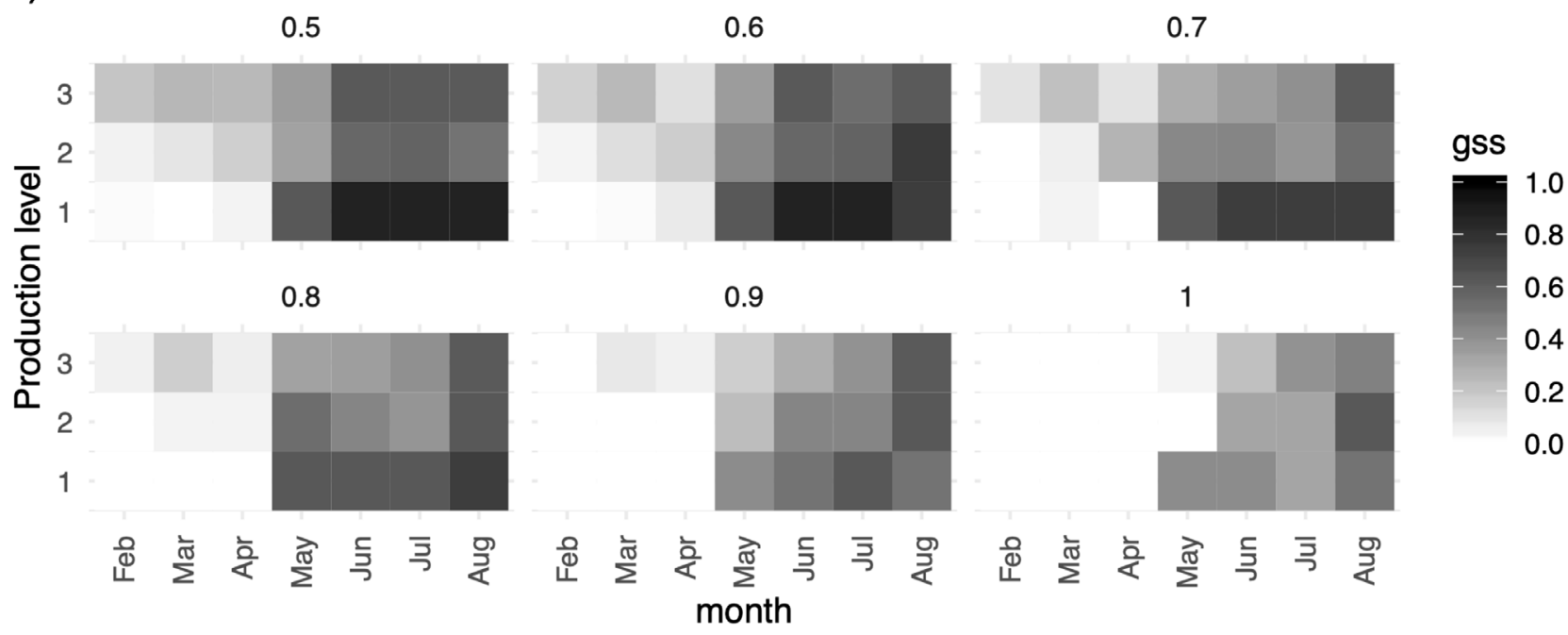

b)

0.5

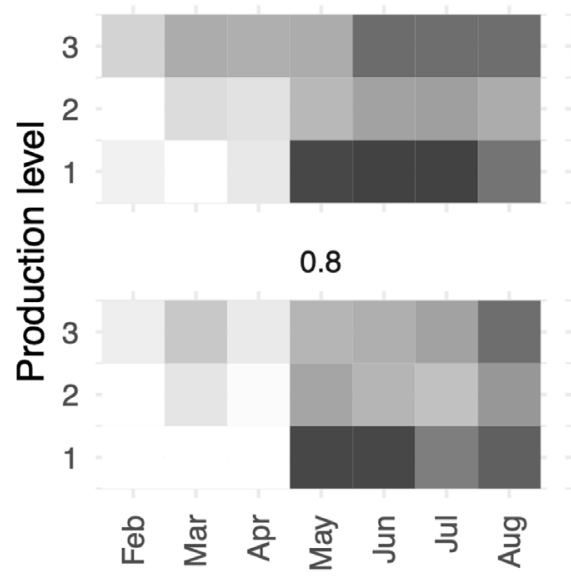

0.6

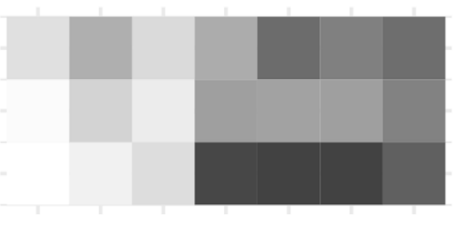

0.9
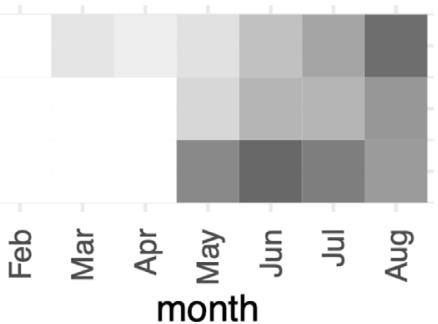

0.7

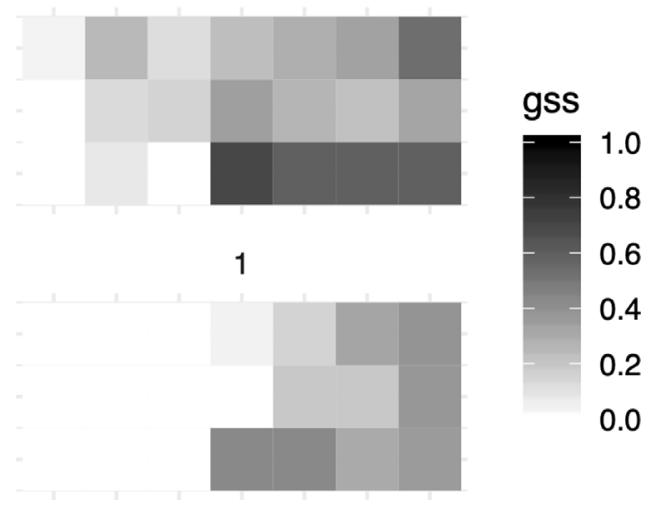

Fig. 7. Performance of wine production predictions by production class and ensemble probability thresholds: Matrix charts of the Gilbert skill scores (GSS, grey shading) of the wine production class forecast, using as reference (a) the estimated class by the wine production model (logistic empirical model) driven by the E-OBS observational data, and (b) the observed production class. GSS are computed using the 51-member ensemble of ECMWF seasonal forecast system initializations, as a function of the forecast month (February to August, $\mathrm{x}$-axis) and for the three wine production classes (1-low, 2-normal and 3-high, y-axis). Different probability thresholds $(0.5,0.6,0.7,0.8,0.9$ and 1.0$)$ are also shown. These thresholds indicate the ratio of seasonal forecast ensemble members that correctly predict the wine production class. GSS ranges from $-1 / 3$ to 1 , with 0 indicating no skill and 1 indicating perfect skill. The grey shading scales are defined for the range from 0 to 1 .

the high potential of the monthly weather forecasts from May to August to predict wine production classes in the D\&P WR.

\section{Discussion and conclusions}

The usefulness of seasonal weather forecasts on predicting wine production has been herein assessed. We have categorized wine production into three classes (low, normal and high production years) and applied multinomial logistic regression to obtain a predictive model of wine production in the Portuguese D\&P WR over the period 1950-2017. In this empirical model, temperature and precipitation averaged over the periods of February-March, May-June and July-September, along with the anomalies of wine production in the previous 5 years, are used as predictors. This wine production model integrates a meteorological component, as in a previous study by Santos et al. (2013), and an autoregressive component. The meteorological component takes into account new variables compared to the previous study, defined over new temporal windows, takes advantage of a gridded observational dataset (E-OBS) and thus establishes more statistically robust relationships between meteorological conditions and the wine production in the D\&P WR. Correct estimation ratios of $79 \%$ (calibration) and of $67 \%$ (validation) are achieved, highlighting a quite satisfactory performance, despite the very simple statistical methodology employed.

A 51-member ensemble from the ECMWF forecast system has been used to produce weather forecasts for the D\&P WR, issued from February to August, with a lead time of 7 months. Forecasts from May to August are generally the best performing, mostly because 1) there is already a considerable part of observed data integrated into the empirical model, and 2) the skill of seasonal forecasts for summer months is generally higher in southern Europe. Furthermore, the skill in the seasonal wine production for high and normal production classes is 
higher when we consider a relatively low threshold for the number of members (close to half of the members).

Overall, the results are very promising, demonstrating significant potential predictability of the wine production in the D\&P WR. Other factors, such as the critical role played by adverse extreme weather events, are not taken into account in the current approach. Hailstorms and heavy precipitation events are relatively frequent in late spring and early summer in the D\&P WR (Santos and Belo-Pereira, 2019), which may underlie significant reductions in wine production, at least at subregional scale. Although the analysis of the relationship between these events and regional wine production is out of the scope of the present study, the need for in-depth dedicated investigation is here pointed out. Nevertheless, the insufficient representation of extremes by the seasonal forecasting system (in terms of intensity and spatial-temporal occurrence) must be taken into account when aiming to incorporate the effects of extreme events. Interesting opportunities may arise from the seamless merging of short-to-medium range weather forecasts (up to two weeks). A unified approach should be envisioned in future research to further enhance the effective value of these predictions for the winemaking sector, not only in Portugal but also in other wine regions worldwide.

The logistic regression approach followed herein is a rather simple method that can be easily implemented in a wide range of applications and decision support platforms. However, the application of more advanced statistical tools, such as those based on machine learning techniques (Alexis et al., 2020), may significantly enhance the current approach in forthcoming research, including the modelling of other crop variables. Seasonal forecasts for other variables relevant to viticulture and winemaking may also be valuable, such as grape berry quality attributes, grapevine stress parameters or the timings of phenological stages. Phenology models have already been developed for the D\&P WR and applied under future climate change scenarios (Costa et al., 2019; Reis et al., 2020). Their application to seasonal weather forecasts should also be foreseen in the near future. The present study can be regarded as a first step towards the implementation of a forecast system for the wine sector in the D\&P WR, and other wine regions in Portugal, which can be operationalized within a consortium with research units, winegrower's associations and the Portuguese Weather Service, amongst other actors. This implementation is of foremost relevance for stakeholders from the winemaking sector, taking into account the high exposure, vulnerability and risk that viticulture is facing under ongoing climate change (Santos et al., 2020b).

\section{Declaration of Competing Interest}

None.

\section{Acknowledgements}

This study was supported by the European Commission-funded project "Climate change impact mitigation for European viticulture: knowledge transfer for an integrated approach - Clim4Vitis" [grant number 810176]. This work was also supported by National Funds by FCT - Portuguese Foundation for Science and Technology [grant number UIDB/04033/2020]. Chloe Prodhomme was supported by the Spanish Juan de la Cierva [IJCI-2016-30802] and has received funding from the EU H2020 Framework Programme IMPREX [grant number 641811], ERA4CS Call 2016 (MedSCOPE) and the HIATUS project [grant number CGL2015-70353-R]. Andrea Toreti and Andrej Ceglar acknowledge support from the H2020 MedGOLD project [grant number 776467].

\section{References}

Alexis, H., Armen, K., Chris, E.F., 2020. The response of maize, sorghum, and soybean yield to growing-phase climate revealed with machine learning. Environ Res Lett.
Andrade, C., Fraga, H., Santos, J.A., 2014. Climate change multi- model projections for temperature extremes in Portugal. Atmos Sci Lett 15 (2), 149-156. https://doi.org/ 10.1002/asl2.485.

Andrade, C., Santos, J.A., Pinto, J.G., Corte-Real, J., 2011. Large-scale atmospheric dynamics of the wet winter 2009-2010 and its impact on hydrology in Portugal. Clim Res 46 (1), 29-41. https://doi.org/10.3354/cr00945.

Balmaseda, M.A., Mogensen, K., Weaver, A.T., 2013. Evaluation of the ECMWF ocean reanalysis system ORAS4. Q J Roy Meteor Soc 139 (674), 1132-1161. https://doi. org/10.1002/qj.2063.

Bernardo, S., Dinis, L.T., Machado, N., Moutinho-Pereira, J., 2018. Grapevine abiotic stress assessment and search for sustainable adaptation strategies in Mediterraneanlike climates. A review. Agron Sustain Dev 38, 66. https://doi.org/10.1007/s13593018-0544-0.

Ceglar, A., et al., 2018. Land surface intialisation improves seasonal climate prediction skill for maize yield forecast. Sci Rep-Uk 8, 1322. https://doi.org/10.1038/s41598018-19586-6.

Cornes, R.C., van der Schrier, G., van den Besselaar, E.J.M., Jones, P.D., 2018. An Ensemble Version of the E-OBS Temperature and Precipitation Data Sets. Journal of Geophysical Research: Atmospheres 123 (17), 9391-9409. https://doi.org/10.1029/ 2017jd028200.

Costa, A.C., Santos, J.A., Pinto, J.G., 2012. Climate change scenarios for precipitation extremes in Portugal. Theor Appl Climatol 108 (1-2), 217-234. https://doi.org/10. 1007/s00704-011-0528-3.

Costa, R., Fraga, H., Fernandes, P.M., Santos, J.A., 2017. Implications of future bioclimatic shifts on Portuguese forests. Reg Environ Change 17 (1), 117-127. https://doi. org/10.1007/s10113-016-0980-9.

Costa, R., et al., 2019. Grapevine Phenology of cv. Touriga Franca and Touriga Nacional in the Douro Wine Region: modelling and Climate Change Projections. Agronomy 9 (4). https://doi.org/10.3390/agronomy9040210.

de Cortazar-Atauri, I.G., et al., 2017. Grapevine phenology in France: from past observations to future evolutions in the context of climate change. Oeno One 51 (2) 115-126. https://doi.org/10.20870/oeno-one.2016.0.0.1622.

Doblas-Reyes, F.J., Garcia-Serrano, J., Lienert, F., Biescas, A.P., Rodrigues, L.R.L., 2013. Seasonal climate predictability and forecasting: status and prospects. Wires Clim Change 4 (4), 245-268. https://doi.org/10.1002/wcc. 217.

Drappier, J., Thibon, C., Rabot, A., Geny-Denis, L., 2019. Relationship between wine composition and temperature: impact on Bordeaux wine typicity in the context of global warming-Review. Crit Rev Food Sci 59 (1), 14-30. https://doi.org/10.1080/ 10408398.2017.1355776.

Du, H., et al., 2012. Sensitivity of decadal predictions to the initial atmospheric and oceanic perturbations. Clim Dynam 39 (7-8), 2013-2023. https://doi.org/10.1007/ s00382-011-1285-9.

Duchene, E., 2016. How Can Grapevine Genetics Contribute to the Adaptation to Climate Change? Oeno One 50 (3), 113-124. https://doi.org/10.20870/oeno-one.2016.50. 3.98.

Falloon, P., et al., 2018. . The land management tool: developing a climate service in Southwest UK. Climate Services 9, 86-100. https://doi.org/10.1016/j.cliser.2017.08. 002.

Fraga, H., Atauri, I.G.D., Malheiro, A.C., Moutinho-Pereira, J., Santos, J.A., 2017a. Viticulture in Portugal: a review of recent trends and climate change projections. Oeno One 51 (2), 61-69. https://doi.org/10.20870/oeno-one.2016.0.0.1621.

Fraga, H., Atauri, I.G.D., Malheiro, A.C., Santos, J.A., 2016a. Modelling climate change impacts on viticultural yield, phenology and stress conditions in Europe. Global Change Biol 22 (11), 3774-3788. https://doi.org/10.1111/gcb.13382.

Fraga, H., Atauri, I.G.D., Santos, J.A., 2018. Viticultural irrigation demands under climate change scenarios in Portugal. Agr Water Manage 196, 66-74. https://doi.org/10. 1016/j.agwat.2017.10.023.

Fraga, H., Costa, R., Santos, J.A., 2017b. Multivariate Clustering of Viticultural Terroirs in the Douro Winemaking Region. Cienc Tec Vitivinic 32 (2), 142-153. https://doi.org/ $10.1051 / \mathrm{ctv} / 20173202142$.

Fraga, H., et al., 2014a. Very high resolution bioclimatic zoning of Portuguese wine regions: present and future scenarios. Reg Environ Change 14 (1), 295-306. https:// doi.org/10.1007/s10113-013-0490-y.

Fraga, H., Malheiro, A.C., Moutinho-Pereira, J., Santos, J.A., 2014b. Climate factors driving wine production in the Portuguese Minho region. Agr Forest Meteorol 185, 26-36. https://doi.org/10.1016/j.agrformet.2013.11.003.

Fraga, H., Molitor, D., Leolini, L., Santos, J.A., 2020. What Is the Impact of Heatwaves on European Viticulture? A Modelling Assessment. Applied Sciences 10 (9). https://doi. org/10.3390/app10093030.

Fraga, H., Santos, J.A., 2018. Vineyard mulching as a climate change adaptation measure: future simulations for Alentejo. Portugal. Agr Syst 164, 107-115. https://doi.org/10. 1016/j.agsy.2018.04.006.

Fraga, H., et al., 2016b. Climatic suitability of Portuguese grapevine varieties and climate change adaptation. Int J Climatol 36 (1), 1-12. https://doi.org/10.1002/joc.4325.

Gouveia, S., Rebelo, J., Lourenco-Gomes, L., 2018. Port wine exports: a gravity model approach. Int J Wine Bus Res 30 (2), 218-242. https://doi.org/10.1108/Ijwbr-022017-0008.

Gudmundsson, L., Bremnes, J.B., Haugen, J.E., Engen-Skaugen, T., 2012. Technical Note: downscaling RCM precipitation to the station scale using statistical transformations a comparison of methods. Hydrol Earth Syst Sc 16 (9), 3383-3390. https://doi.org/ 10.5194/hess-16-3383-2012.

Leolini, L., et al., 2020. Phenological Model Intercomparison for Estimating Grapevine Budbreak Date (Vitis vinifera L.) in Europe. Applied Sciences 10 (11). https://doi. org/10.3390/app10113800.

Magalhães, N., 2008. Tratado De viticultura: a videira, a Vinha e o Terroir. Chaves Ferreira, Lisboa, Portugal. 
Malheiro, A.C., et al., 2013. Winegrape Phenology and Temperature Relationships in the Lisbon Wine Region, Portugal. J Int Sci Vigne Vin 47 (4), 287-299. https://doi.org/ 10.20870/oeno-one.2013.47.4.1558.

Molteni, F., et al., 2011. The new ECMWF seasonal forecast system (System 4). United Kingdom.

Moriondo, M., et al., 2015. Modelling olive trees and grapevines in a changing climate. Environ Modell Softw 72, 387-401. https://doi.org/10.1016/j.envsoft.2014.12.016.

Mosedale, J.R., Abernethy, K.E., Smart, R.E., Wilson, R.J., Maclean, I.M.D., 2016. Climate change impacts and adaptive strategies: lessons from the grapevine. Global Change Biol 22 (11), 3814-3828. https://doi.org/10.1111/gcb.13406.

OIV, 2018. OIV Statistical Report On World Vitiviniculture. International Organization of Vine and Wine, Paris, France.

Prata-Sena, M., Castro-Carvalho, B.M., Nunes, S., Amaral, B., Silva, P., 2018. The terroir of Port wine: two hundred and sixty years of history. Food Chem 257, 388-398. https://doi.org/10.1016/j.foodchem.2018.03.014.

Prodhomme, C., Doblas-Reyes, F., Bellprat, O., Dutra, E., 2016. Impact of land-surface initialization on sub-seasonal to seasonal forecasts over Europe. Clim Dynam 47 (3-4), 919-935. https://doi.org/10.1007/s00382-015-2879-4.

Reis, S., et al., 2020. Grapevine Phenology in Four Portuguese Wine Regions: modeling and Predictions. Applied Sciences 10 (11). https://doi.org/10.3390/app10113708.

Santos, J.A., Andrade, C., Corte-Real, J., Leite, S., 2009. The role of large-scale eddies in the occurrence of winter precipitation deficits in Portugal. Int J Climatol 29 (10), 1493-1507. https://doi.org/10.1002/joc.1818.

Santos, J.A., Belo-Pereira, M., 2019. A comprehensive analysis of hail events in Portugal: climatology and consistency with atmospheric circulation. Int J Climatol 39 (1), 188-205. https://doi.org/10.1002/joc.5794.

Santos, J.A., Belo-Pereira, M., Fraga, H., Pinto, J.G., 2016. Understanding climate change projections for precipitation over western Europe with a weather typing approach. J Geophys Res-Atmos 121 (3), 1170-1189. https://doi.org/10.1002/2015JD024399.

Santos, J.A., Costa, R., Fraga, H., 2019a. New insights into thermal growing conditions of Portuguese grapevine varieties under changing climates. Theor Appl Climatol 135 (3-4), 1215-1226. https://doi.org/10.1007/s00704-018-2443-3.

Santos, J.A., et al., 2020a. A Review of the Potential Climate Change Impacts and
Adaptation Options for European Viticulture. Applied Sciences 10 (9). https://doi. org/10.3390/app10093092.

Santos, J.A., Gratsch, S.D., Karremann, M.K., Jones, G.V., Pinto, J.G., 2013. Ensemble projections for wine production in the Douro Valley of Portugal. Climatic Change 117 (1-2), 211-225. https://doi.org/10.1007/s10584-012-0538-x.

Santos, J.A., Malheiro, A.C., Karremann, M.K., Pinto, J.G., 2011. Statistical modelling of grapevine yield in the Port Wine region under present and future climate conditions. Int J Biometeorol 55 (2), 119-131. https://doi.org/10.1007/s00484-010-0318-0.

Santos, M., Fonseca, A., Fraga, H., Jones, G.V., Santos, J.A., 2020b. Bioclimatic conditions of the Portuguese wine denominations of origin under changing climates. Int $\mathrm{J}$ Climatol 40 (2), 927-941. https://doi.org/10.1002/joc.6248.

Santos, M., Fonseca, A., Fragoso, M., Santos, J.A., 2019b. Recent and future changes of precipitation extremes in mainland Portugal. Theor Appl Climatol 137 (1-2), 1305-1319. https://doi.org/10.1007/s00704-018-2667-2.

Scaife, A.A., et al., 2014. Skillful long-range prediction of European and North American winters. Geophys Res Lett 41 (7), 2514-2519. https://doi.org/10.1002/ 2014 GL059637.

Smart, R.E., 1985. Principles of Grapevine Canopy Microclimate Manipulation with Implications for Yield and Quality - a Review. Am J Enol Viticult 36 (3), 230-239 $\mathrm{n} / \mathrm{a}$

Turco, M., et al., 2017. Summer drought predictability over Europe: empirical versus dynamical forecasts. Environ Res Lett 12 (8), 084006. https://doi.org/10.1088/ 1748-9326/Aa7859.

van Leeuwen, C., et al., 2004. Influence of climate, soil, and cultivar on terroir. Am J Enol Viticult 55 (3), 207-217 n/a.

Wang, L., Ting, M., Kushner, P.J., 2017. A robust empirical seasonal prediction of winter NAO and surface climate. Sci Rep-Uk 7, 279. https://doi.org/10.1038/s41598-01700353-y.

Weisheimer, A., Doblas-Reyes, F.J., Jung, T., Palmer, T.N., 2011. On the predictability of the extreme summer 2003 over Europe. Geophys Res Lett 38, L05704. https://doi. org/10.1029/2010gl046455.

Wilks, D.S., 1995. Statistical Methods in the Atmospheric Sciences: An Introduction. Academic Press, New York, USA, pp. 467. 